\title{
Characterization of domestic gray water from point source to determine the potential for urban residential reuse: a short review
}

\author{
Golda A. Edwin · Poyyamoli Gopalsamy • \\ Nandhivarman Muthu
}

Received: 9 July 2012 / Accepted: 9 September 2013/Published online: 26 September 2013

(C) The Author(s) 2013. This article is published with open access at Springerlink.com

\begin{abstract}
This study aims to discern the domestic gray water (GW) sources that is least polluting, at the urban households of India, by examining the GW characteristics, comparing with literature data, reuse standards and suitable treatment technologies. In view of this, the quantitative and qualitative characteristics of domestic $\mathrm{GW}$ originating from bath, wash basin, laundry and kitchen sources are determined and compared with established standards for reuse requirements. Quality of different gray water sources is characterized with respect to the physical, chemical, biological, nutrient, ground element and heavy metal properties. The pollutant loads indicate that the diversion techniques are not suitable for household application and, therefore, treatment is necessary prior to storage and reuse. It is observed that the total volume of GW generated exceeds the reuse requirement for suggested reuse such as for flushing and gardening/irrigation. In spite of generating less volume, the kitchen source is found to be the major contributor for most of the pollutant load and, therefore, not recommended to be considered for treatment. It is concluded that treatment of GW from bathroom source alone is sufficient to meet the onsite reuse requirements and thereby significantly reduce the potable water consumption by $28.5 \%$. Constructed wetland systems and constructed soil filters are suggested as suitable treatment alternatives owing to its ability to treat highly variable pollutant load
\end{abstract}

G. A. Edwin · P. Gopalsamy · N. Muthu

Department of Ecology and Environmental Sciences, School of Life Sciences, Pondicherry University, R. Venkataraman Nagar, Kalapet, Puducherry 605014, India

G. A. Edwin $(\bowtie)$

No 23, Kamaraj Salai, Thattanchavady, Puducherry 605009, India

e-mail: golda_edwin@yahoo.in with lower operational and maintenance cost, which is more practical for tropical and developing countries.

Keywords Gray water composition · Gray water treatment - Water treatment technologies - Urban water reuse $\cdot$ Domestic gray water

\section{Introduction}

One of the most pressing problems of today is water scarcity. It has been estimated that one in three persons will face water scarcity by the year 2025 in India (IWMI 2003) or around 2.7 billion people worldwide by the same time (UN Report 2003). In the recent past, there is comparatively increased awareness among the governments and bodies dealing with water management to address the challenges related to water security. Measures to reduce water usage through increased awareness, installation of rainwater harvesting and gray water (GW) treatment systems are seen as promising solutions, especially in developing countries that are more vulnerable to water scarcity (NEERI 2007a). GW reuse is increasingly emerging as an integral part of water demand management, providing water for non-potable residential and industrial use (EA Report 2001). Moreover, the economics of wastewater management and treatment have become a crucial topic of discussion due to the following reasons (Poyyamoli et al. 2013):

- Wastewater management is a significant and growing problem, especially in urban areas of both the developed and developing world.

- The available fresh water sources are dwindling and are getting scarce. 
- Increase in fresh water pollution due to human activities.

- Increase in health hazards and ecosystem damage due to uncontrolled discharge of wastewater into streams and oceans.

- The inefficient or ineffective system of wastewater treatment in developing countries.

In general, gray water means wastewater generated from domestic activities such as bath, hand basins, washing machines, dishwashing, laundry and kitchen. It does not include wastewater from toilet. It is considered to be the largest potential source of water reuse option at point source, accounting for around 50-80 \% of the total water use (Christova-Boal et al. 1996; Eriksson et al. 2002; Jamrah et al. 2006). Recent scientific advancement in costeffective GW treatment for non-potable reuse (including gardening, irrigation and toilet flushing) suggest that there is a great potential for $\mathrm{GW}$ reclamation and reuse in the developing world. However, reclamation and reuse of $\mathrm{GW}$ from bathroom/shower sources alone is of particular interest to urban reuse due to its low pollution load and high availability (Jefferson et al. 1999). In addition, GW from kitchen sources is considered to be less favorable for reuse due to its high concentration of pollutant load. This study deals with the characterization of $\mathrm{GW}$ to better understand the physical, chemical, microbial and nutrient composition of GW from Indian households. The study also aims to explore various cost-effective treatment options available for point source treatment and reuse.

The number, lifestyle, age, presence of children, health status and water usage patterns of the occupants are found to affect the characteristics of GW generated in a household (NSW 2007). The composition of gray water varies widely from household to household and is highly dependent on the detergents, cosmetics and other personal habits of residents. Gray water from homes with children tends to contain higher counts of coliform than the homes without children. Gray water is typically characterized by very high concentrations of biodegradable organic material, such as fats and oils from cooking, and xenobiotic compounds and other residues from soap and detergents. Though the presence of pathogenic microbes is minimal in GW (Mara and Kramer 2008), it favors the growth of microbes and can turn anoxic, emanating foul odor if left untreated for more hours. Therefore, point source treatment and reuse is considered favorable as it not only enables the treatment of $\mathrm{GW}$ is as soon as it is generated, but also it reduces the load on the centralized treatment facility supported by the local municipalities. In India, the goal of every state should be to become water independent through proper planning to avoid conflicts with neighboring states in case of water dependency. Standards for GW reuse were suggested by the central pollution control board (CPCB) and are presented in Table 1 along with the existing WHO and USEPA standards.

Gray water characteristics also vary according to its origin and for this reason; the least contaminated sources of household gray water should be prioritized for reuse. The literature data reveal that $\mathrm{GW}$ from bathroom sources accounts for about 50-60 percent of total GW (Loh and coghlan 2003; Poyyamoli et al. 2013) and are contaminated with large quantities of oils, body fats and chemicals originating from soap, shampoo, hair dyes, toothpaste, nutrients and from other cleaning products. It also contains traces of fecal contamination (NSW 2007). The GW from laundry sources accounts for about $4 \%$ of total GW (Loh and coghlan 2003) and all washing requirements account about 25-30 \% of total GW (Poyyamoli et al. 2013). It is generally more contaminated than bathroom GW (Jeppesen and Solley 1994; christova-Boal et al. 1996) and may contain oils, trace elements and chemicals from detergents, soaps and nutrients and can also contain fecal contamination in traces. Of all sources, Kitchen GW is considered to be the most contaminated with contaminants such as food particles, oil and grease. It accounts for around $10 \%$ of total GW and is even not considered as GW by some and should be treated using appropriate technology prior to reuse. According to Friedler (2004), the gray water from kitchen and dishwasher should be excluded as they contribute nearly 50 percent of its COD requirement.

\section{Materials and methods}

This investigation is aimed at characterizing the GW that is generated at residential premises. Both quantitative and qualitative analysis are performed as a part of this investigation. The study independently samples and assesses the physical, chemical, microbiological, nutrients, ground elements and heavy metals properties of GW generated from bath/shower, wash basin, kitchen and laundry sources. The analysis of xenobiotic compounds is not considered as part of this study. A total of 32 sets of samples for each GW source are collected from eight independent single family households comprising of infants and people with a wide distribution of ages. The GW samples were collected from the outlet of each source within $2 \mathrm{~h}$ from production and were mostly analyzed immediately or kept sealed and stored under cold and dry conditions $\left(<5{ }^{\circ} \mathrm{C}\right)$ for a maximum of a day. The control samples were collected from the drinking water taps. The collected samples were analyzed for $\mathrm{pH}$ and $\mathrm{EC}$ using the respective meters, whereas the other parameters were determined through the standard laboratory methods (APHA 2005). The results were compared to the published literature data. 


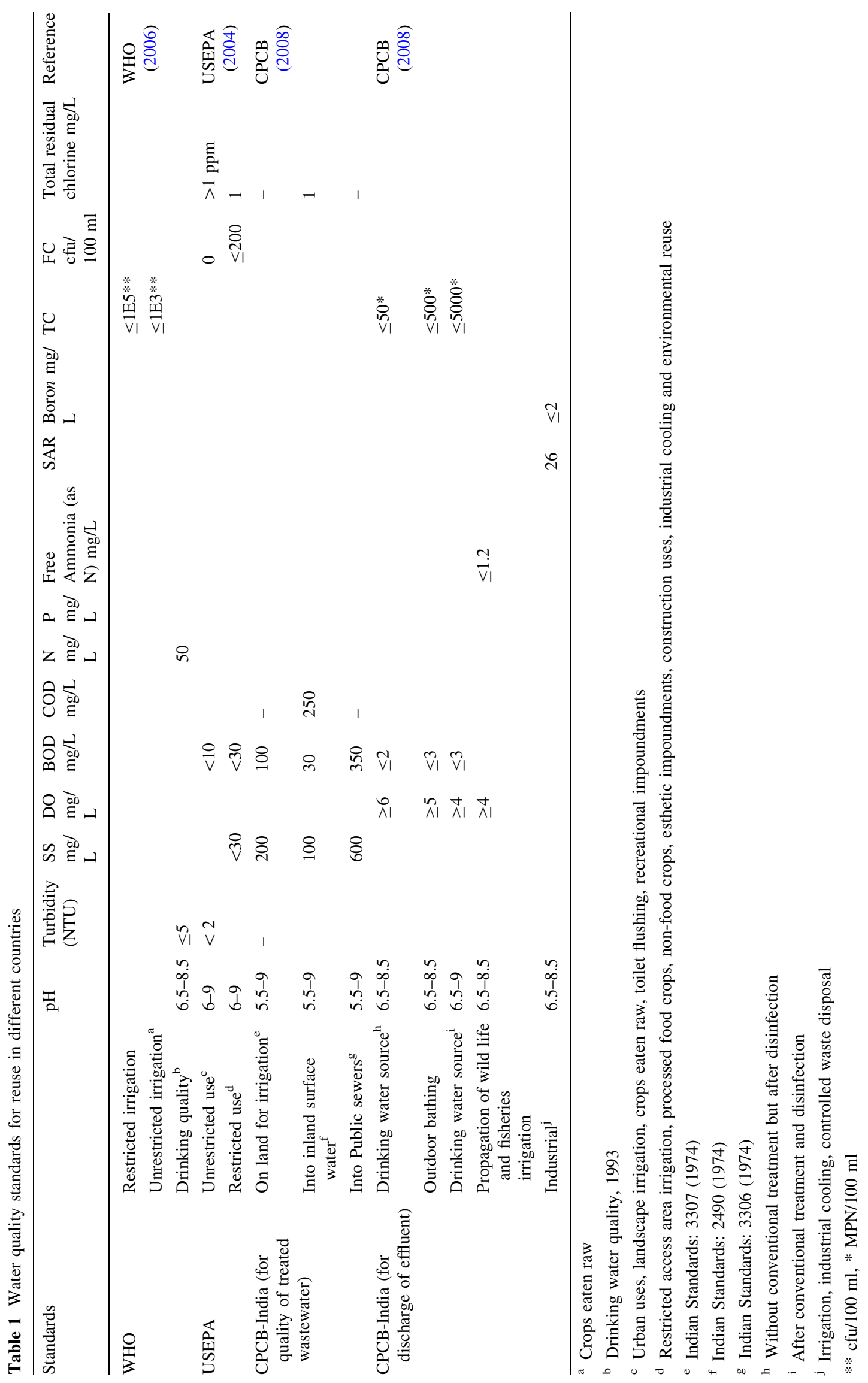




\section{Results and discussion}

The quantitative characteristics of GW produced from various sources are shown in Table 2, and the qualitative characteristics are shown in Tables 3 and 4. The relative distribution of total water consumption and GW production is shown in the Fig. 1. The results indicate that the mean total water consumption is significantly high when compared with the literature data of other Indian cities. This shows that the urban households consume more water compared to the rural ones. On an average, $62 \%$ of GW is generated with major contribution from the bathroom (49\%), followed by laundry, kitchen and wash basin sources.

The characteristics indicate high variability in the physical, chemical, biological parameters among the different sources. The GW from kitchen sources contribute to over half of all pollutant load (Fig. 2), followed by laundry and bathroom sources. The trace elements and heavy metals indicate no additional treatment is required for nonpotable reuse, whereas the BOD, COD and other nutrient concentrations indicate that further treatment is necessary to meet the effluent standards for reuse. The laundry and kitchen GW have high concentrations of phosphorus due to

Table 2 Quantity of GW produced from various sources compared with literature data

\begin{tabular}{|c|c|c|c|c|}
\hline Source & $\begin{array}{l}\text { This study } \\
\mathrm{Lp}^{-1} \mathrm{~d}^{-1} \\
\text { mean (sd) }\end{array}$ & $\begin{array}{l}\text { Literature }^{\mathrm{a}} \\
\mathrm{Lp}^{-1} \mathrm{~d}^{-1} \\
\text { mean }\end{array}$ & $\begin{array}{l}\text { Literature } \\
\mathrm{Lp}^{-1} \mathrm{~d}^{-1} \\
\text { mean }\end{array}$ & $\begin{array}{l}\text { Literature }^{\mathrm{c}} \\
\mathrm{Lp}^{-1} \mathrm{~d}^{-1} \\
\text { mean }\end{array}$ \\
\hline $\begin{array}{l}\text { Total water } \\
\text { consumption }\end{array}$ & $114(27.34)$ & 50 & 91.56 & 127.5 \\
\hline $\begin{array}{l}\text { Drinking and } \\
\text { cooking use }\end{array}$ & $3.5(0.84)$ & 10 & 6.59 & 1.8 \\
\hline Toilet flushing & $30(7.19)$ & 7.5 & 18.31 & 37.1 \\
\hline $\begin{array}{l}\text { Gardening } \\
\text { irrigation/ } \\
\text { others }\end{array}$ & $2.5(0.6)$ & NIL & 2.20 & \\
\hline $\begin{array}{l}\text { Washing and } \\
\text { cleaning of } \\
\text { house }\end{array}$ & 7 (1.68) & 3.5 & 6.68 & \\
\hline $\begin{array}{l}\text { Total GW } \\
\text { production }\end{array}$ & $71(17.03)$ & 29 & 57.77 & 88.6 \\
\hline $\begin{array}{l}\text { Shower and } \\
\text { bath }\end{array}$ & 35 (8.39) & 15 & 25.82 & 52.3 \\
\hline Hand basin & $5(1.2)$ & NIL & NIL & 5.3 \\
\hline Laundry & $19(4.56)$ & 10 & 17.03 & 17.2 \\
\hline $\begin{array}{l}\text { Kitchen/ } \\
\text { dishwashing }\end{array}$ & $12(2.88)$ & 4 & 14.92 & 13.8 \\
\hline
\end{tabular}

${ }^{a}$ GW reuse in rural schools (NEERI 2007b)

b Study conducted on seven Indian Cities (Delhi, Mumbai, Kolkata, Hyderabad, Kanpur, Ahmadabad, Madurai) (Abdul and Sharma 2007)

c Studies on Dutch water consumption (Foekema et al. 2008) the choice of detergents used. The $\mathrm{COD} / \mathrm{BOD}_{5}$ ratios (Table 5) indicate potential for biodegradability for aerobic treatment options except for laundry GW. However, comparison of the COD:N:P ratio with the optimal values of 100:20:1 as reported in Metcalf and Eddy (2003) indicate severe nitrogen deficiency and is in agreement with the literature values (Huelgas et al. 2009). The COD:BOD ratio for the combined gray water is found to be $3: 1$ which according to Jefferson et al. 2004, can approach 4:1, which is much higher than that of domestic wastewater $(2: 1)$.

\section{Prospects and hazards of GW reuse}

One of the biggest prospects of reusing treated GW is the reduction in fresh water demand and black water footprint, thereby enabling the municipal systems to lower the cost and increase treatment effectiveness. In spite of several reuse options that are considered relatively safe, there are different factors that influence the selection of reuse requirement, including effluent quality, technology, supply and demand, infrastructure, economic feasibility and environmental considerations (Asano et al. 2007). The potential hazards of reusing the treated $\mathrm{GW}$ can be of physical, chemical and biological in nature. The physical hazards include water volume and contaminants that are physical in nature. The chemical hazards include the salts, nutrients and chemicals originating from various sources and the biological ones are due to the pathogens present in $\mathrm{GW}$. The major problem is that the affected environment can either be within the residential premises affecting humans, animals, soil health or it can even extend beyond the premise affecting the neighboring areas (NSW 2007). Risk in this case is a source of danger; a possibility of incurring loss through mismanagement of GW treatment systems or by not taking enough precautions in determining the potential usage of treated GW complying with the standards.

Presently, there are no uniform quality standards for gray water reuse, and the available treatment technologies are mostly proprietary and unclear on many aspects. Also, there are no laws or regulations on the treatment and reuse of GW in many countries including India (Allen et al. 2010). In the US, guidelines exist at the state level and several states have developed legislation to allow gray water reuse in different circumstances. California was the first state to study and permit the reuse of gray water. Kitchen sinks are not allowed in many states with some exceptions like Montana (gray wateraction.org). Cyprus has subsidized gray water reuse systems for households that wish to install one for domestic landscaping and toilet flushing (Kambanellas 1998). Rainwater systems are preferred over gray water recycling systems by households in Germany due to the higher quality water available from the 


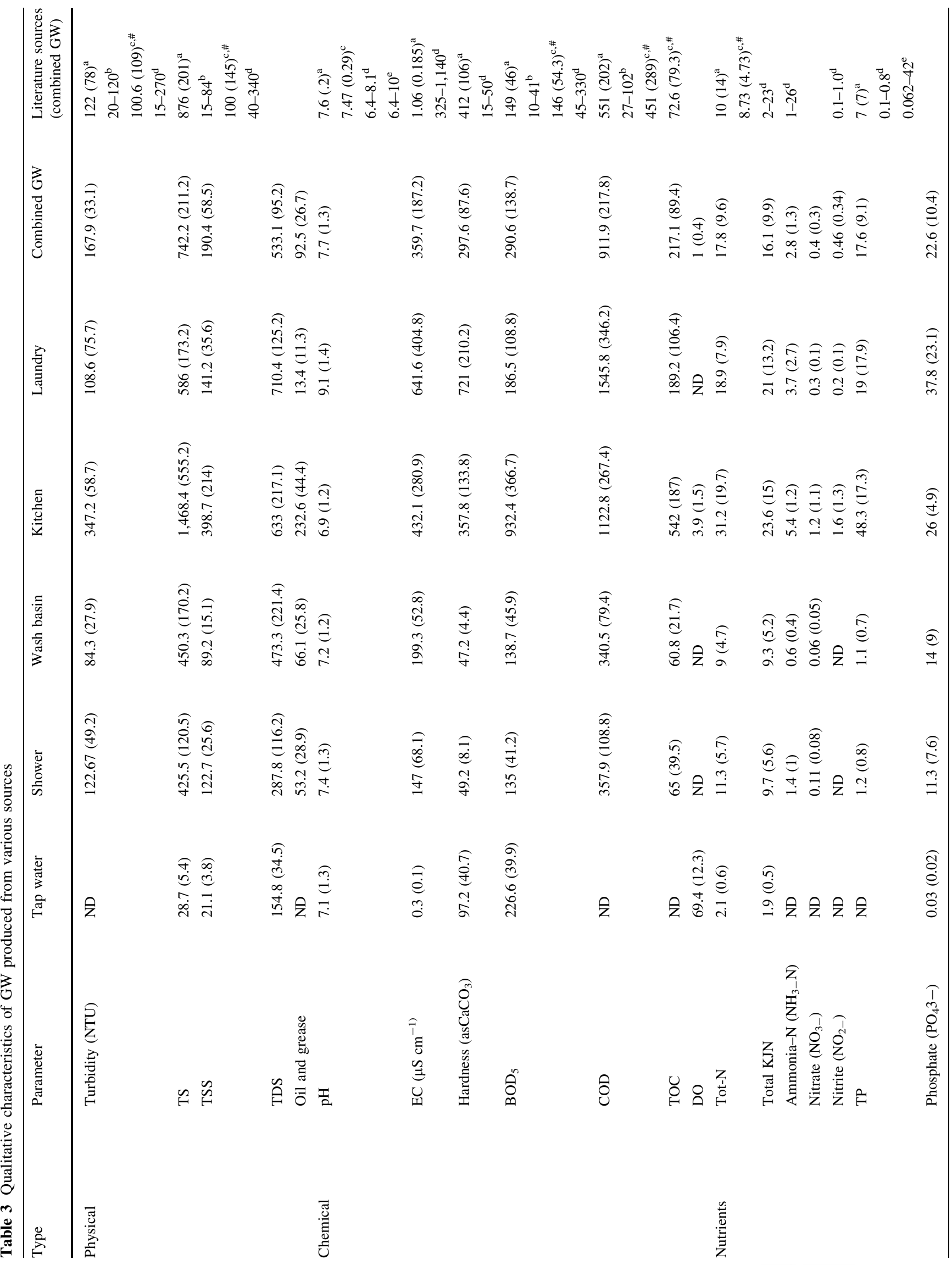




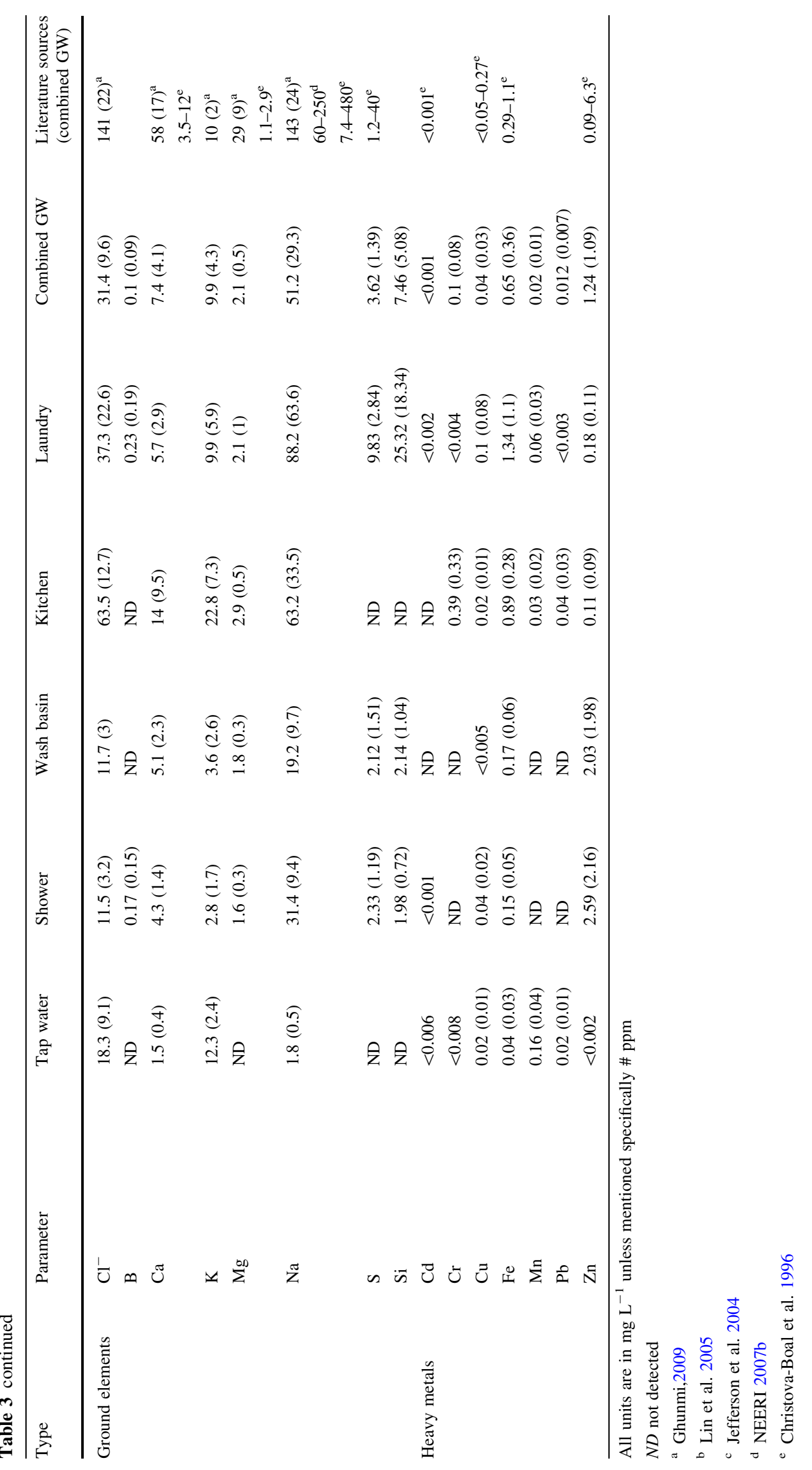


Table 4 Microbial characteristics of GW produced from various sources

\begin{tabular}{llllllll}
\hline Parameter & Tap water & Shower & Wash basin & Kitchen & Laundry & Combined GW & Literature sources (combined GW) \\
\hline Total coliform & $1.72-1.87$ & $3.95-6.28$ & $2.94-6.95$ & $3.38-5.11$ & $3.04-5.6$ & $6.99-7.71$ & $7,387(9,759)^{\mathrm{c}, \#}$ \\
E. coli & $0.85-1.15$ & $2.98-3.06$ & $2.81-2.95$ & ND & ND & $3.54-6.3$ & $3.8^{\mathrm{b}}$ \\
& & & & & & & $2,022(5,956)^{\mathrm{c}, \#}$ \\
\hline
\end{tabular}

All units are in $\log 10.100 \mathrm{ml}$ unless specified \#cfu/100 ml

$N D$ not detected

a Ghunmi 2009

b Lin et al. 2005

c Jefferson et al. 2004

d NEERI 2007b

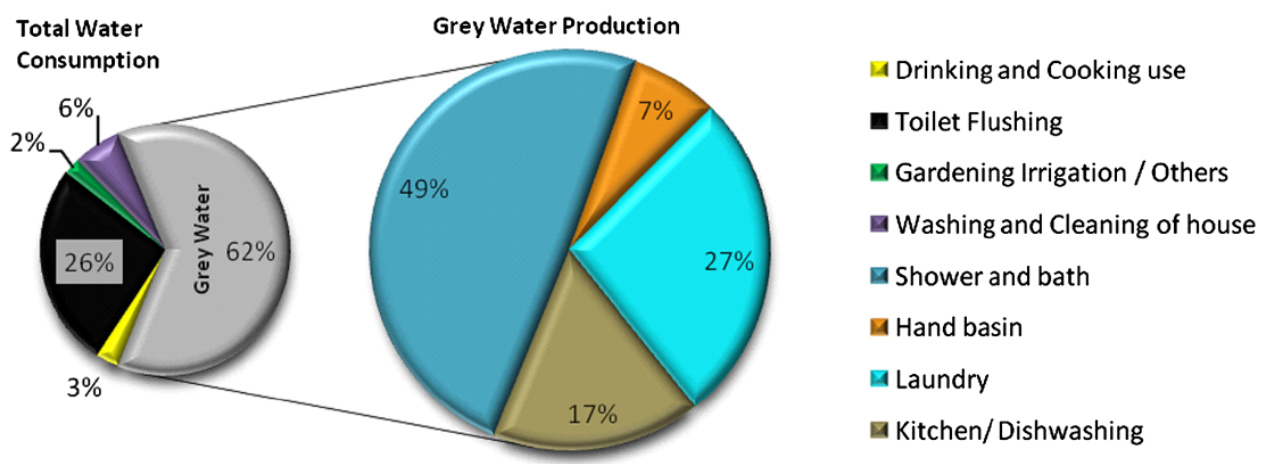

Fig. 1 The relative distribution of total water consumption and GW production

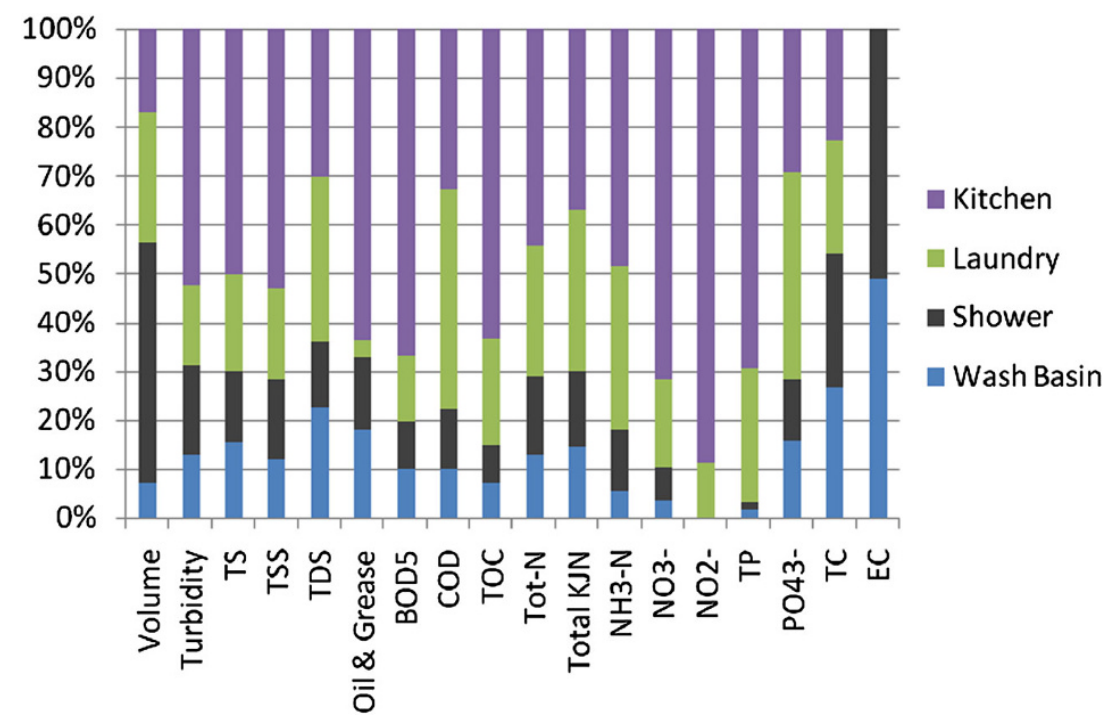

Fig. 2 The relative pollutant load in gray from different point of origination

rain. In Tokyo, gray water recycling is mandatory for buildings with an area over $30,000 \mathrm{~m}^{2}$ or with potential reuse of $100 \mathrm{~m}^{3} /$ day (Hanson 1997). Limited freshwater availability in places like Singapore and Namibia are being augmented by adding highly treated gray water to their drinking water.
In India, only recently the Brihanmumbai Municipal Corporation (BMC) of the Indian state of Mumbai has passed the by-laws to make it mandatory for all new residential and commercial building to have rainwater harvesting system and also GW reuse system. Recycling of water is also a condition under the Jawaharlal Nehru 
Table 5 Key ratios for biodegradability of GW

\begin{tabular}{lll}
\hline GW Source & COD/BOD 5 ratio & COD:N:P ratio \\
\hline Shower & 2.7 & $100: 3.2: 0.3$ \\
Wash basin & 2.5 & $100: 2.6: 0.3$ \\
Kitchen & 1.2 & $100: 2.8: 4.3$ \\
Laundry & 8.3 & $100: 1.2: 1.2$ \\
Combined & 3.1 & $100: 2: 1.9$
\end{tabular}

National Urban Renewal Mission (JNNURM) to get funds for projects in India, which is an encouraging step towards better water security and sustainability.

In general, there is a lowered health risks associated with GW reuse than those of combined raw wastewater. In the developed part of the world, the countries that promote research and reuse of GW include UK, USA, Canada, Japan, Germany, Israel, Sweden and Australia. Though the treatment and reuse of GW at a community level would prove to be economically advantageous, some countries like UK had seen huge acceptance for reuse within households (Bixio et al. 2006). However, in developing countries like India and others, GW treatment and reuse are still in a primitive stage, and decentralized option for GW treatment would prove to be beneficial in these environments. Reuse for toilet flushing alone can reduce the water demand by $10-20 \%$ which is very significant in the water stress regions (Friedler 2004), and reuse for toilet flushing and garden irrigation can reduce by up to $50 \%$ (Maimon et al. 2010).

Other than household reuse, GW reuse is also favorable for irrigation, industrial reuse and potable reuse. Reuse for irrigation is most favorable in tropical countries. However, accumulation of sodium and other micro-pollutants over a long period are to be researched as only a few short-term studies are done which suggests that micro-pollutants are degraded in soil over time (Ternes and Joss 2006; Hernández Leal 2010). Most common industrial reuse of treated GW is for the purpose of cooling (Asano et al. 2007). Thought the reuse for direct potable purpose is considered a taboo in many parts of the world mainly due to the public perception (du Pisani 2006), its applicability may sound a good idea in water stress or water scarce regions. Distinct water quality standards should be assigned to different types of wastewater reuse and the guidelines should be framed keeping in mind the risks associated with specific source of gray water.

\section{Technology selection}

There are various technologies for gray water treatment, varying in their forms, complexity, treatment method, and location (indoor or outdoor). The factors that influence the selection of appropriate technology includes the volume of
$\mathrm{GW}$, organic strength, energy requirement, reuse application, socio-economic factors, geographic location and public acceptance. The primary goal should be to prevent the need for treatment by reducing the volume of $\mathrm{GW}$ generation through various water conservation techniques or by decreasing the pollutant load using environmental friendly household products that are biodegradable and non-toxic. Otherwise, there are a wide range of physical, chemical and biological technologies that have been used for GW treatment and reuse. There is no universally accepted design for gray water treatment and it is largely designed in accordance with gray water source, quantity, quality, site specifications, reuse options and patterns (Finley et al. 2009). One thing that is well established is the fact that gray water intended for treatment and reuse should not be stored for longer periods of time as this encourages the growth of microbial population present in it (Winward et al. 2008). Disinfection and filtration techniques are primarily utilized in the physical/chemical GW treatment systems, whereas the biological treatment uses aeration and membrane bioreactors. The most common treatment systems seen across the world are membrane bioreactors, sequence batch reactors and biologically aerated filters which produce high quality effluent. However, these are generally power consuming and involve high capital costs, therefore not suitable for decentralized implementation in low- and middle-income countries (Allen et al. 2010). In the arid regions of southern US, Australia, Middle Eastern countries and India, simple gray water diverting schemes are common for irrigating landscape plants. In Germany and Scandinavia, high water prices led to sophisticated gray water treatment systems that involve active aeration (Finley et al. 2009). The major challenge in treating domestic gray water is its variable nature, which is dependant on the type of household product choices and habits of the residents. In view of this, the system should be designed to work at a small scale without much use of technology (Kadewa 2010).

\section{Diversion systems}

These include systems that divert gray water for outdoor landscape irrigation, for toilet flushing and systems that divert gray water to treatment wetlands. This is perhaps the simplest form of gray water reuse, mostly from the laundry or bathroom sinks to a subsurface garden irrigation system or toilet flushing. Spraying gray water for irrigation is not recommended as it may come in contact with humans. These techniques are mostly gravity based without the use of any electricity. This involves very low capital and maintenance, and there is no storage involved which increases the risk of microbial growth. However, these systems does not kill or reduce the disease causing 
pathogens that may be present thereby limiting the option for reuse.

\section{Physical and chemical gray water treatment}

The physical- and chemical-based gray water treatment systems primarily utilize disinfection and filtration techniques. The disinfection techniques are mainly based on chlorine, ultraviolet or ozone effected treatment. These are highly efficient in destroying disease causing bacteria and other microbes if properly designed and operated. However, they are found to create toxic byproducts, especially the chlorine- and ozone-based systems. Among these three types, chlorine-based is most economical followed by UV and ozone-based systems.

Electro-coagulation is another type of non-biological technology to treat gray water. It involves adding coagulating metal ions to the gray water using electrodes. These ions in turn coagulate the contaminants and cause it to settle or float, so that it can be easily removed. However, these require high capital and operational costs with complex operations.

Sand filters are a common filtration technique, which requires less cost, simple operation and low maintenance. It consists of beds of sand or other media and treats gray water through physical filtration of impurities or through bio-filtration, which involves physical particulate separation, and the adsorption and bio-degradation of soluble and particulate organic contaminants from the gray water. Gray water is passed through a grease trap and sedimentation tank prior to passing through the sand filter to avoid clogging. These types of filters do not totally eliminate the pathogens. Another form of filtration is through activated carbon, which is treated with oxygen to make it porous enough at a microscopic level to adsorb impurities from gray water. However, the filter needs to be replaced once all the pores are filled and it also does not remove all types of impurities.

\section{Biological gray water treatment}

Biological treatment systems primarily use aeration techniques and membrane bioreactors. Aeration techniques produce higher effluent quality compared to filtration techniques. As part of this system, oxygen is transferred into the gray water through bubbling. This in turn causes the bacteria to multiply and breakdown the organic pollutants. Membrane bioreactors use aerobic biological treatment with filtration techniques for better efficiency and usually disinfected before reusing the treated water. These types of systems however involve higher capital and operational costs.

From the study, the average BOD/COD ratio of 2.6 from bath/wash basin sources favors the aerobic treatment.
However, the COD:N:P ratio indicates low concentrations of Nitrogen, since most of the nutrients are discharged into the black water and is in agreement with the literature (Jefferson et al. 1999; Huelgas et al. 2009). Therefore, frequent monitoring and adjustments of nutrient content are a precondition for optimal microbial breakdown and a satisfactory long-term performance of such treatment systems. The natural (soil-based and aquatic-based) treatment systems are proving to be a better alternative for water treatment gaining popularity, especially in developing countries. Vertical and horizontal flow constructed wetland systems (CWS) and the recently developed constructed soil filters (CSF)/Soil Bio Technology (SBT), which work by simulating the fundamental natural processes such as respiration, mineral weathering and photosynthesis, are recommended for their ability to treat low nutrient GW and produce a high quality effluent with fewer maintenance, less energy consumption, and relatively low capital/operational cost than mechanical systems.

There are different types of CWS designs that are used to treat wastewater. The horizontal subsurface CWS are reported to have an efficient removal of COD and TSS; however, the removal of TN and TP is generally low in this system (Konnerup et al. 2009). On the other hand, the vertical flow CWS are good at removing nitrogen (Lee and Scholz 2007) indicating a hybrid design using both horizontal and vertical flow CWS might produce more satisfactory results. Although the constructed wetland technology is well established, there are fewer studies involving native species for the treatment of domestic gray water. The SBT system is a relatively new and emerging technology patented by the Indian Institute of Technology, Mumbai. This utilizes the native micro flora, geophagus worm and bio-indicator plants as a medium and has been reported for high removal of $\mathrm{COD}, \mathrm{BOD}, \mathrm{N}, \mathrm{SS}$ and turbidity. The microbial pathogens are also significantly reduced through the highly toxic potential and near neutral $\mathrm{pH}$ together with the ecology of the environment (Kadam et al. 2008, 2009). Though the reclaimed water may contain traces of xenobiotic compounds from household products, the risk associated to this is still needs to be thoroughly researched. Though most of such compounds are non-toxic to humans, accumulation of such micro-pollutants over time in a closed loop system may be a problem. Awareness would be needed to enable the residents to choose ecofriendly household products with high biodegradability thereby reducing the risk associated with micro-pollutants.

\section{Conclusion}

The research showed that the quality of GW with respect to $\mathrm{COD}, \mathrm{BOD}, \mathrm{TS}$ and pathogens requires adequate 
treatment prior to household reuse. With regard to the trace and heavy metal contents, no further treatment is required. The bath/wash basin sources contribute to around $56 \%$ of total GW, but are found low in nutrient load and BOD. However, it is high in turbidity, suspended solids, COD and EC. The laundry GW is found to be high in hardness, SS, TOC and COD. Of all GW sources, the kitchen sink contributes to less volume but very high in turbidity, SS, BOD, TOC, COD and overall pollutant load. The COD/BOD 5 ratio of laundry $\mathrm{GW}(8.3)$ is found to be very high, while that of bath/wash basin GW (2.6) is low indicating its suitability for biological treatment. However, the COD: $\mathrm{N}: \mathrm{P}$ ratio indicates the insufficiency of nitrogen concentration for aerobic treatment. It is estimated that the treatment of GW from bathroom source alone is sufficient to meet the onsite reuse requirements, and thereby significantly reduces the potable water consumption by $28.5 \%$. The natural treatment systems such as the CWS and SBT are recommended considering the low cost, less maintenance and its suitability for the developing countries.

Open Access This article is distributed under the terms of the Creative Commons Attribution License which permits any use, distribution, and reproduction in any medium, provided the original author(s) and the source are credited.

\section{References}

Abdul S, Sharma RN (2007) Water consumption pattern in domestic households in major Indian Cities, Economic and Political Weekly. Vol. XLII No. 23

Allen L, Smith JC, Palaniappan M (2010) Overview of gray water reuse: the potential of gray water systems to aid sustainable water management, Pacific Institute

APHA (2005) Standard methods for the examination of water and waste water. American Public Health Association, 21st edition. Washington

Asano T et al (2007) Water reuse: issues, technologies, and applications, 1st edn. Metcalf and Eddy, Inc., McGraw-Hill, New York

Bixio D, Thoeye C, De Koning J, Joksimovic D, Savic D, Wintgens T, Melin T (2006) Wastewater reuse in Europe. Desalination 187(1-3):89-101

Christova-Boal D, Evans RE, McFarlane S (1996) An investigation into gray water reuse for urban residential properties. Desalination 106:391-397

CPCB (2008) Performance of sewage treatment plants-coliform reduction. Central Pollution Control Board. Ministry of Environment and Forests, New Delhi

Du Pisani PL (2006) Direct reclamation of potable water at Windhoek's Goreangab reclamation plant. Desalination 188(1-3):79-88

EA Report (2001) Water resources for the future-a strategy for England and Wales. Environment Agency, London

Eriksson E, Auffarth K, Henze M, Ledin A (2002) Characteristics of gray wastewater. Urban Water 4:85-104

Finley S, Barrington S, Lyew D (2009) Reuse of domestic gray water for the irrigation of food crops. Water Air Soil Pollut 199(1-4):235-245
Foekema H, van Thiel L, Lettinga B (2008) Watergebruik thuis 2007 [Water use at home 2007]. (C6026). Amsterdam. TNS NIPO

Friedler E (2004) Quality of individual domestic gray water streams and its implication for on-site treatment and reuse possibilities. Environ Technol 25(9):997-1008

Ghunmi LNAA (2009) Characterization and treatment of gray water; options for (re)use. Wageningen Universiteit (Wageningen University)

Hanson L (1997) Environmentally friendly systems and products: water saving devices. Department of Environment, Transport and the Regions, Bracknell: BSRIA

Hernández Leal L (2010) Removal of micropollutants from gray water: combining biological and physical/chemical processes [Sl: sn] http://graywateraction.org/content/about-graywater-reuse Accessed 27 May 2013

Huelgas A, Nakajima M, Nagata H, Funamizu N (2009) Comparison between treatment of kitchen-sink wastewater and a mixture of kitchen-sink and washing-machine wastewaters. Environ Technol 30:111-117

IWMI (2003) International Water Management Institute, Water Policy Briefing-8

Jamrah A, Al-Omari A, Al-Qasem L, Abdel Ghani N (2006) Assessment availability and characteristics of gray water in Amman. Int Water Resour Assoc 31(2):210-220

Jefferson B, Laine A, Parsons S, Stephenson T, Judd S (1999) Technologies for domestic wastewater recycling. Urban Water 1(4):285-292

Jefferson B, Palmer A, Jeffrey P, Stuetz R, Judd S (2004) Gray water characterisation and its impact on the selection and operation of technologies for urban reuse. Water Sci Technol 50(2):157-164

Jeppesen, B, Solley D (1994) Domestic gray water reuse: overseas practice and its applicability to Australia. Urban Water Research Association of Australia

Kadam AM, Oza GH, Nemade PD, Shankar HS (2008) Pathogen removal from municipal wastewater in constructed soil filter. Ecol Eng 33:37-44

Kadam AM, Nemade PD, Oza GH, Shankar HS (2009) Treatment of municipal wastewater using laterite-based constructed soil filter. Ecol Eng 35:1051-1061

Kadewa WW (2010) Small-scale constructed wetland for onsite light gray water treatment and recycling

Kambanellas CA (1998) Recycling of gray water in Cyprus. Water Development Department, Nicosia

Konnerup D, Koottatep T, Brix H (2009) Treatment of domestic wastewater in tropical, subsurface flow constructed wetlands planted with Canna and Heliconia. Ecol Eng 35:248-257

Lee BH, Scholz M (2007) What is the role of Phragmites australis in experimental constructed wetland filters treating urban runoff? Ecol Eng 29:87-95

Lin C, Lo S, Kuo C, Wu C (2005) Pilot-scale electro-coagulation with bipolar aluminium electrodes for on-site domestic gray water reuse. J Env Eng 131(3):491-495

Loh M, Coghlan P (2003) Domestic water use study Perth, Water Corporation

Maimon A, Tal A, Friedler E, Gross A (2010) Safe on-site reuse of gray water for irrigation-a critical review of current guidelines. Environ Sci Technol 44:3213-3220

Mara D, Kramer A (2008) The 2006 WHO Guidelines for wastewater and gray water use in agriculture: a practical interpretation. In: Al Baz I, Otterpohl R, Wendland C (eds) Efficient management of wastewater. Springer Berlin, Heidelberg

Metcalf and Eddy (2003) Wastewater engineering treatment and reuse, fourth Edition. Tata McGraw-Hill Publications, pp 551-555

NEERI (2007a) Guidance manual for water quality monitoring and assessment (First Edition), October 2007. National Environmental Engineering Research Institute (Neeri), Nehru Marg, Nagpur 
NEERI (2007b) Guidance manual gray water reuse in rural Schools. National Environmental Engineering Research Institute, India

NSW (2007) New South Wales Government. NSW guidelines for gray water reuse in sewered, single household residential premises. Department of Energy Utilities and Sustainability, Sydney

Poyyamoli G, Golda AE, Nandhivarman M (2013) Constructed wetlands for the treatment of domestic grey water: an instrument of the green economy to realize the millennium development goals. The Economy of Green Cities, Springer Netherlands, pp 313-321

UN Report (2003) Water for people, water for life. World Water Development Report (WWDR). Unesco And Berghahn Books
Ternes T, Joss A (2006) Human pharmaceuticals, hormones and fragrances: the challenge of micropollutants in urban water management. IWA, London

USEPA (United States Environmental Protection Agency) (2004) Guidelines for water reuse. Report EPA/625/R-04/108, USEPA, Washington

WHO (2006) WHO Guidelines for the safe use of wastewater, excreta and gray water, 3rd Edition, Volume II. Wastewater Use in Agriculture. World Health Organisation, Geneva

Winward GP, Avery LM, Frazer-Williams R, Pidou M, Jeffrey P, Stephenson T, Jefferson B (2008) A study of the microbial quality of gray water and an evaluation of treatment technologies for reuse. Ecol Eng 32(2):187-197 